\title{
La educación sentimental
}

\author{
Selen Arango Rodríguez
}

La educación es un arte antiguo que involucra prácticas y técnicas milenarias. Es decir, es imposible ubicar el momento en el cual los seres humanos comenzamos a recibir educación. Solo sabemos que, desde sus inicios, la educación ha estado conformada por una serie de saberes que se transmiten de una generación a otra, que es una praxis íntimamente relacionada con la cultura y que, a partir del siglo XIX, fue reducida a la escolarización.

En la Edad Media aparece una figura vinculada a la idea de educación: la del maestro. Esta figura la refiere Santo Tomás al considerar que el maestro no transmite conocimientos, sino que aparece cuando el discípulo no puede seguir aprendiendo por sí mismo. Así, debe ayudarse de su maestro interior dado por Dios. La he nombrado figura porque no se remite a un individuo; más bien, a la conciencia y a la autonomía, a lo que más adelante, en el marco de la tradición pedagógica alemana, se nombrará formación (Bildung). La palabra formación, en la lengua alemana, es cercana a la palabra cultura, por lo que es difícil definirla, pero que en este texto será entendida como aquello que hemos ganado como civilización.

La novela de formación es, tal vez, el género literario que recuerda la historicidad de la educación y ayuda a comprender la formación humana como un proceso abierto y permanente que termina en el momento en el que dejamos este mundo. La novela de formación no se escribe con la intención de enseñar algo. Sin embargo, las novelas pueden formar y educar a quienes las leemos, describir el proceso de formación de quienes las protagonizan y esclarecer qué hacemos los seres humanos con lo que nos pasa.
La educación sentimental de Gustave Flaubert fue publicada en Francia en 1869 y describe los aprendizajes de Frédéric Moreau en el contexto de una sociedad parisina que aún estaba comprendiendo la Revolución francesa y estaba debatiéndose entre la burguesía y la democracia. Esta novela es una parodia pormenorizada de las costumbres y formas de relacionarse de la sociedad francesa del siglo XIX a partir de sus distinciones morales.

Frédéric recoge las características del personaje principal de una novela de formación, a saber: un héroe que se desplaza del entorno familiar o zona de confianza para vivir una serie de aventuras y peripecias individuales que le permiten regresar a casa o consolidar su adultez a través de la realización del proyecto de sí. No le importan las problemáticas de interés público. En algunas novelas, en medio de su proceso, el héroe puede encontrarse con una persona que toma el lugar de maestro o de guía en su periplo. En el caso de la novela de Flaubert, el héroe, Frédéric, tendrá como maestro al señor Arnoux debido a que no tiene una idea muy clara de lo que quiere hacer de sí. Es un joven que se forma por las circunstancias y aventuras que desencadenan sus sentimientos. De ahí que la novela lleve el nombre de La educación sentimental, en tanto Frédéric es objeto de sus sentimientos.

La novela está dividida en tres partes, en las cuales analizará la idea de educación sentimental que sostiene la narración. En la primera parte, la educación sentimental está unida a las formas como Frédéric lucha con el amor platónico que tiene hacia Marie, la esposa del señor Arnoux. En este apartado, el joven solo observa a Marie, como si lo hiciera desde una 
ventana. Hacia el final, tienen su primera conversación en donde el joven abordó

[...] el capítulo de las aventuras sentimentales, y ella compadecía los desastres de la pasión, pero le indignaban las infamias hipócritas; y aquella rectitud de espíritu correspondía tan bien con la belleza correcta de su rostro que parecía su consecuencia (p. 146).

La idea de educación en este capítulo se relaciona con el inicio de la profesionalización, pues el narrador nos cuenta que Frédéric quería ser diplomático y para ello viaja a París a estudiar derecho. Pero también, con la figura del maestro. En la novela de formación, el maestro no es quien enseña en un aula, sino quien emula la conciencia. En la novela de Flaubert, el señor Arnoux no será la conciencia de Frédéric, pero sí el tipo de hombre que quiere llegar a ser.

En la segunda parte, el joven asiste a su primer baile por invitación del señor Arnoux. Al inicio de la velada, al observar la voluptuosidad de las mujeres y sentirlas cerca, percibe una "[...] sensación de abandono, un malestar" (p. 184). Entonces, al llegar a su casa, antes de dormir, el narrador nos advierte que Moreau tenía sed y que "otra sed se le había despertado: la de las mujeres, la del lujo y de todo lo que lleva en sí la vida parisiense" (p. 197). En la fiesta conoce a la mariscala, Rosanette, quien él mismo decide que será su amante. Ella, a su vez, lo era del señor Arnoux. Entonces, en este capítulo, se profundizará en cómo Frédéric intenta diferenciar entre deseo y amor a través de la comparación entre lo que serán para él Rosanette y Marie, la señora Arnoux. En algún momento, piensa lo siguiente:

El trato de aquellas dos mujeres sonaba en su vida como dos músicas: la una alegre, ardiente, divertida [Rosanette]; la otra, grave y casi religiosa [Marie]. Porque si la señora Arnoux le rozaba tan solo con un dedo, la imagen de la otra inmediatamente se presentaba a su deseo, porque de este lado era menos lejana la esperanza; y cuando al lado de Rosanette llegaba su corazón a conmoverse, se acordaba de su gran amor (pp. 216-217).

Decide, entonces, conquistar a Rosanette, por ser más alcanzable desde su ventana. En algún momento, se cuestiona engañar a su amigo Arnoux, quien también visita a Rosanette, pero piensa que tiene el derecho a no ser respetuoso con su amante, pero sí con su esposa. En esta parte, nos enteramos de que el señor Arnoux regala las mismas cosas a su esposa y a su amante, lo cual, también, hace Frédéric, pero con promesas de amor. En una ocasión, la señora Arnoux increpa a su esposo sobre su infidelidad, pero él niega cada una de las pruebas que ella tiene; más adelante, Frédéric le confiesa su amor, pero ella no le corresponde. En esta parte, Frédéric se queda sin dinero y debe regresar a su casa. Allí pasa un tiempo y conoce a la hija de Roque, Luise, una niña que heredará el dinero de su padre. Recibe una carta en la que se le informa que su tío ha muerto y se alegra porque pronto recibirá su herencia y podrá regresar a París y continuar observando a su amor platónico.

En la tercera parte, la narración se encamina a describir cómo finalmente Frédéric ha logrado ser como el señor Arnoux: infiel, cínico, despilfarrador, en el marco de una sociedad parisina interesada en derrocar la aristocracia francesa que aún sigue siendo corrupta y antidemocrática. En este apartado vemos cómo Frédéric permite que su madre lo comprometa con Luise, pues imagina lo que podría hacer con su herencia. Inicia un romance con Rosanette, quien queda en embarazo y da luz en una clínica de madres solteras, a escondidas de la sociedad parisiense. Pasa la noche con ella y con su hijo, y en las tardes, comparte el tiempo con la señora Arnoux. Cuando recuerda que quiere ser un diplomático, se acerca a la señora Dembruse en el lecho de su esposo moribundo para declararle su amor y prometerle ma- 


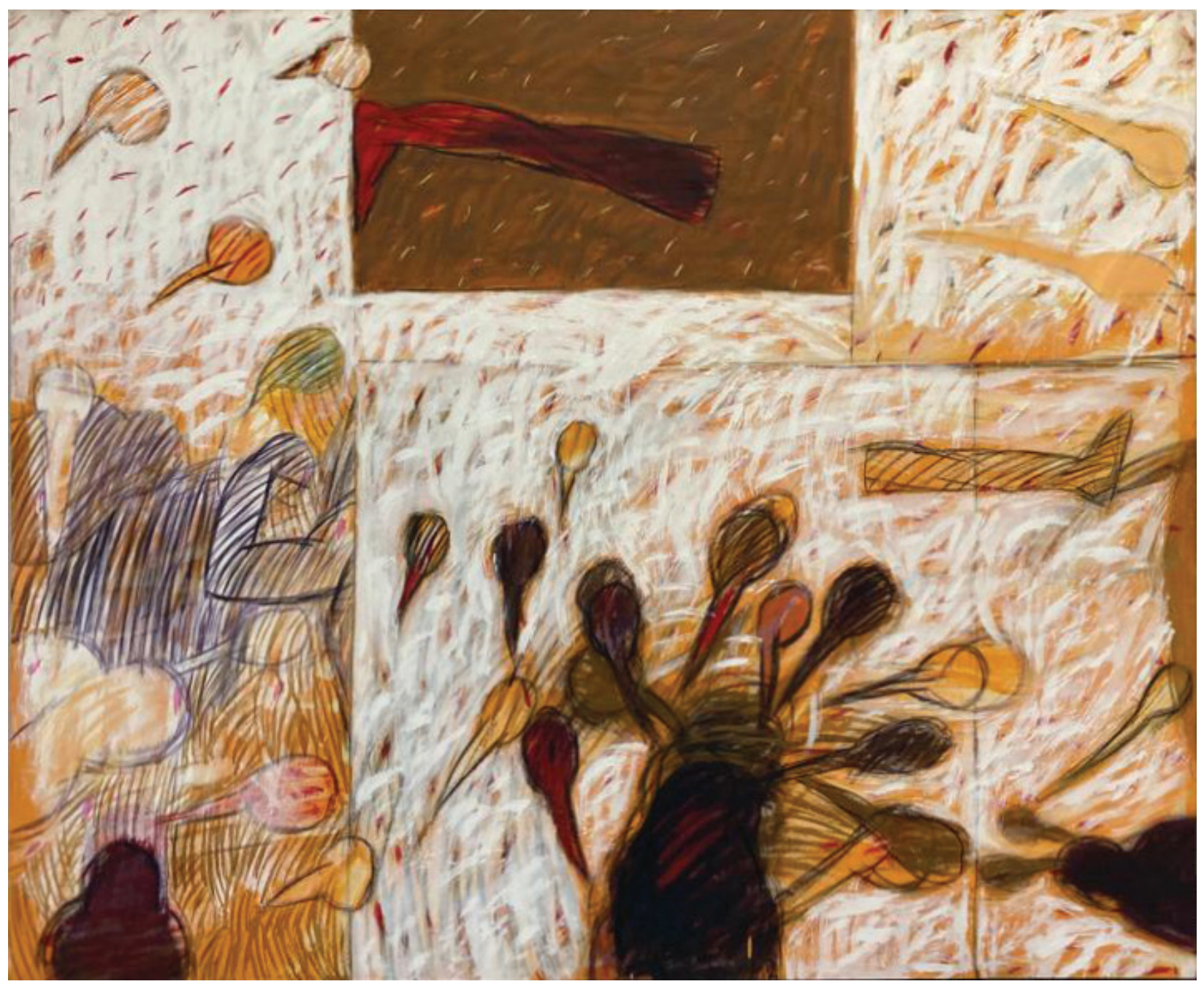

trimonio. Hacia el final de este capítulo, han pasado unos diez años, y Marie, más adulta, con su pelo largo y canoso, sin la belleza de la morena que posó en su mente un ideal romántico, lo busca. Él está separado de su esposa, la viuda Dembruse. La señora Arnoux le confiesa que lo ha amado desde siempre, y Frédéric siente lo siguiente:

[...] algo inexplicable, una repulsión y como el horror de un incesto. Otro temor le detuvo; el de un disgusto futuro. Además ¡qué obstáculo sería aquello! Y a la vez, por prudencia y para no degradar su ideal, dio media vuelta y se puso a liar un cigarrillo. Le contemplaba ella maravillada (p. 534).
Ella se despide y le deja un mechón de su cabello. Él la ve alejarse, desde el lugar desde donde siempre la contempló: la ventana.

Bajtín, en su texto La novela de educación y su importancia en la historia del realismo (1979) escribe que en los géneros de la novelística de los siglos XVII y XVIII, se va incorporando argumentalmente la conciencia del hombre como sujeto de la historia. Así, el contexto histórico de la novela, la Revolución francesa, no influye en la formación de Frédéric, ni tampoco en su propia historia, pues no la tiene. A lo largo de la novela, el único "logro" de Frédéric es llegar a ser como su maestro, el señor Arnoux, un hombre que enamora a las mujeres sea porque 
le atraen físicamente o porque de ellas puede obtener algo para su ascenso social. También que tiene novia, amante y que hace promesas de matrimonio a jóvenes del campo y viudas. Mujeres como la señora Dembruse, la viuda, serán su plataforma política, más no los vínculos que pueda tener con hombres banqueros o políticos.

Moretti, en The Way of the World. The Bildungsroman in European Culture (1987), escribe que la novela de formación es el género literario de la modernidad. A través de ella se divulgaron las ideas de los hombres y de las mujeres que debían sostener la idea de una identidad nacional. Frédéric Moreau es un héroe que fracasa en términos de la promesa de la modernidad: razón sin corazón. Sus sentimientos son los que interceptan su trayecto formativo, aquello que la modernidad quiso amputar de la vida a través de la hegemonía del método o de la emergencia de metódicas que fundamenFlaubert se burla de la frivolidad de la clase burguesa de su época, que vive de las rentas y de sus herencias y ven el trabajo como un pasatiempo o un requisito burocrático.

Doris Sommer, en Ficciones fundacionales. Las novelas nacionales de América Latina (2004), escribe que entre 1850 y 1880 se produjeron los romances que imaginaron las sociedades civiles mediante patrióticos héroes que, como el joven Werther de Goethe, debían dejar que la pasión jamás se antepusiera a la razón conservando su apariencia delicada y unos sentimientos idealizados hacia sus compañeras. Frédéric se quedó en la idealización del amor, inmerso en una educación sentimental en la que se sostuvo a través de la novela. No fue un héroe patriótico en el marco de la Revolución francesa, y tampoco conquistó la nación a través del matrimonio.

Frédéric inicia la figura del antihéroe de la novela de formación. Un personaje que se educa por fuera de la escuela, el lugar nombrado por la modernidad para ser educado. La educación en la novela de Flaubert no es un ente social, como se entiende en el marco de la tradición pedagógica francesa. La educación de Frédéric es el reflejo de algo que viene transitando a través de las generaciones y que hoy se mantiene a través de las telenovelas: la educación sentimental donde las mujeres solo aspiran a ser amadas y los hombres a valerse de esta aspiración para satisfacer su deseo. Para ello, logran que una sea la amada y la otra la amante.

Así, entonces, puedo decir que Flaubert, sin ser pedagogo o nombrado como tal, nos ha legado un conocimiento sobre cómo la educación sentimental aún hace parte del espectáculo social. Su obra, más allá de narrarnos la sociedad francesa del siglo XIX, nos inquieta como seres humanos, cruzados no solo por la historia, sino también por nuestros sentimientos.

\section{Fuente}

Flaubert, G., (2016). La educación sentimental (trad. PierreMarc de Biasi), Penguin Random House.

Selen Arango Rodríguez. Escritora y doctora en Pedagogía por la Universidad Nacional Autónoma de México, especializada en pedagogías contemporáneas y en la relación pedagogía y literatura. Docente de las facultades de Educación, Comunicaciones y Filología y Enfermería, así como del Instituto de Filosofía, de la Universidad de Antioquia. Investigadora adscrita al Grupo de Investigación Salud de las Mujeres de la Facultad de Enfermería de la misma Universidad. 